\title{
Métodos de preservação de Acidovorax avenae subsp. citrulli *
}

\author{
Dário Venâncio de Araújo ${ }^{1}$, Rosa de Lima Ramos Mariano ${ }^{1,2}$, Elineide Barbosa da Silveira ${ }^{1,2}$, Sami Jorge Michereff ${ }^{1,2}$
}

${ }^{1}$ Universidade Federal Rural de Pernambuco, Depto. de Agronomia - Área de Fitossanidade, 52171-030, Recife, PE, e-mail: rmariano@ truenet.com.br. ${ }^{2}$ Bolsista de Produtividade em Pesquisa do CNPq.

*Parte da dissertação de Mestrado do primeiro autor.

Autor para correspondência: Rosa de Lima Ramos Mariano

Data de chegada: 27/10/2006. Aceito para publicação em: 10/10/2007

1410

\section{RESUMO}

Araújo, D.V.; Mariano, R.L.R.; Silveira, E.B.; Michereff, S.J. Preservação de Acidovorax avenae subsp. citrulli. Summa Phytopathologica, v.34, n.2, p.178-180, 2008

Acidovorax avenae subsp. citrulli (Aac), agente da mancha-aquosa, causa grandes prejuízos ao melão e outras cucurbitáceas no Brasil e no mundo. Os métodos dessecação em papel de filtro, repicagens periódicas, água esterilizada e folhas herborizadas foram testados para preservação de Aac1 e Aac1.12 durante 180 dias. Mensalmente, a viabilidade de Aac foi avaliada pelo crescimento em meio de cultura e a patogenicidade das culturas viáveis foi avaliada pela incidência e severidade da doença em plântulas de melão. A preservação em papel de filtro resultou em $100 \%$ de viabilidade dos isolados durante o período, enquanto que nos demais métodos houve perda de viabilidade no decorrer das avaliações. Os métodos de dessecação em papel de filtro e o de repicagens periódicas foram mais eficientes que a água esterilizada e folhas herborizadas na manutenção da patogenicidade dos isolados durante os 180 dias.

Palavras-chave adicionais: Cucumis melo, viabilidade, incidência, índice de doença

\section{ABSTRACT}

Araújo, D.V.; Mariano, R.L.R.; Silveira, E.B.; Michereff, S.J. Preservation of Acidovorax avenae subsp. citrulli. Summa Phytopathologica, v.34, n.2, p.178-180, 2008

The phytopathogenic bacteria Acidovorax avenae subsp. citrulli (Aac), agent of bacterial blotch, causes severe damages to melon and other cucurbits in Brazil and worlwide. The methods desiccation in filter paper, periodic transfer, sterile water and dried leaves were tested for preserving the strains Aac1 and Aac1.12 of this bacterium during 180 days. Evaluations of bacterial viability were performed monthly by growing strains on culture media. The pathogenicity of viable cultures was evaluated by disease incidence and severity on melon seedlings. The desiccation in filter paper maintained $100 \%$ viability of the strains during the period while using the other methods, viability was lost during evaluations. Desiccation in filter paper and periodic transfer were more efficient than sterile water and dried leaves in maintening strain pathogenicity during the time evaluated 180 days.

Additional keywords: Cucumis melo, viability, incidence, disease index

No Brasil, a mancha-aquosa do meloeiro (Cucumis melo L.), causada pela bactéria Acidovorax avenae subsp. citrulli (Schaad et al.) Willems et al. (Aac), tem ocasionado grandes perdas na produção e depreciação no valor comercial de frutos, principalmente nos Estados do Rio Grande do Norte e Ceará (4). Tendo em vista a importância da doença no Brasil e no mundo, são necessários estudos etiológicos, ecológicos e epidemiológicos visando a obtenção de subsídios para seu controle. Esses estudos requerem que culturas puras sejam preservadas pelo maior período de tempo possível, sem ocorrência de mutações, variabilidade (7) ou perda de viabilidade e patogenicidade. Jones et al. (3) recomendaram que isolados do gênero Acidovorax fossem preservados por período curto em meio de cultura YDC a temperatura ambiente e por período longo a $-80^{\circ} \mathrm{C}$. No entanto, nem sempre há equipamento disponível para emprego do segundo método. Considerando que não foi encontrada na literatura consultada uma comparação de métodos de preservação que possibilitasse recomendar uma ou mais técnicas adequadas à manutenção específica de culturas viáveis e patogênicas de Aac (4), isto constituiu o objetivo do presente trabalho.

Culturas dos isolados Aac1 e Aac1.12, pertencentes a Coleção de Culturas do Laboratório de Fitobacteriologia da UFRPE, foram preservadas pelos métodos de dessecação em papel de filtro, repicagens periódicas, água esterilizada e folhas herborizadas. Amostras foram retiradas mensalmente por um período de 180 dias e avaliadas em relação à viabilidade e patogenicidade.

O método de dessecação em fitas de papel de filtro foi realizado como descrito em Mariano \& Silveira (5). A cada avaliação mensal, de cada repetição, uma fita de papel de filtro foi plaqueada em meio ágar nutritivo-extrato de levedura-dextrose (NYDA).

No método de repicagens periódicas, os isolados foram cultivados 


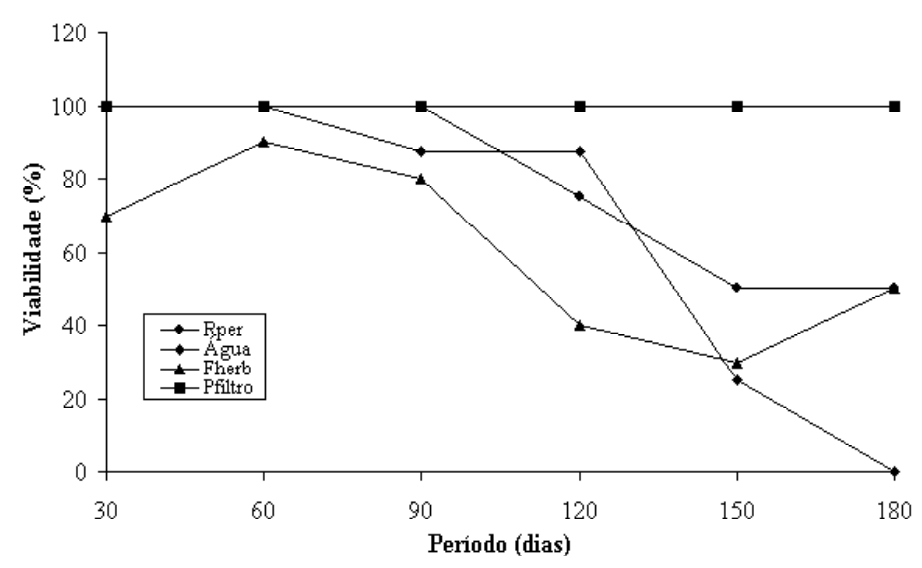

Figura 1. Viabilidade de Acidovorax avenae subsp. citrulli, preservada pelos métodos de repicagens periódicas (Rper), água de torneira esterilizada (Água), folhas com sintomas herborizadas (Fherb) e dessecação em tiras de papel de filtro (Pfiltro), avaliada pelo crescimento após repicagem (Rper, Água e Pfiltro) ou reisolamento (Fherb) aos 30; 60; 90; 120; 150 e 180 dias. Média de dois isolados.

em tubos de ensaio com meio NYDA por $48 \mathrm{~h}$ e conservados a $4^{\circ} \mathrm{C}$. A cada avaliação mensal, de cada repetição, foram feitas repicagens para tubos contendo NYDA. Após 48 h, as culturas viáveis foram novamente armazenadas em geladeira.

Na preservação em água esterilizada, os isolados foram cultivados em NYDA por $48 \mathrm{~h}$, sendo preparadas suspensões em água de torneira esterilizada com $9 \times 10^{8} \mathrm{cel} \mathrm{mL}^{-1}$ (Escala de McFarland), as quais foram transferidas para tubos de criogenia com capacidade de $1,5 \mathrm{~mL}$. Os tubos foram armazenados à temperatura ambiente e a cada avaliação mensal, de cada repetição, $0,1 \mathrm{~mL}$ foi plaqueado em meio NYDA.

Na preservação em folhas herborizadas, plantas de melão com 20 dias após emergência foram inoculadas por pulverização sem ferimento (1). Após o aparecimento dos sintomas, as folhas foram herborizadas por oito dias em papel jornal contido entre grades de madeira e colocadas em envelopes de papel, os quais foram armazenados em condições de laboratório. A cada avaliação mensal, de cada repetição, a partir de uma lesão por folha, foi realizado o isolamento do patógeno em meio NYDA.

$\mathrm{O}$ experimento foi realizado em delineamento inteiramente casualizado, em arranjo fatorial $2 \times 4$, sendo dois isolados do patógeno e quatro métodos de preservação. Foram utilizadas quatro repetições para os três primeiros métodos e cinco repetições para folhas herborizadas.

A viabilidade dos isolados foi avaliada pelo crescimento bacteriano no meio NYDA. Nos casos de viabilidade positiva, a patogenicidade foi testada em cinco plântulas atomizadas com

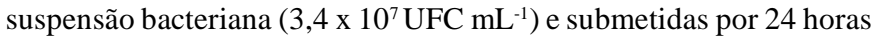
a câmara úmida. A avaliação da incidência e severidade da manchaaquosa foi realizada após sete dias, com o auxílio de escala de notas (1), sendo calculados o índice de doença (6), a área abaixo da curva de incidência da doença e a área abaixo da curva do índice de doença (8).

Não houve diferença significativa $(\mathrm{P}=0,05)$ entre os isolados de Aac, os quais foram analisados conjuntamente. No estudo da viabilidade dos isolados preservados pelos quatro métodos (Figura 1), observou-se que a dessecação em tiras de papel de filtro proporcionou viabilidade constante durante o período de 180 dias. Este método tem sido utilizado para manutenção de bactérias por períodos de até 12 anos (9). Já as repicagens periódicas mantiveram $100 \%$ de viabilidade durante 90 dias. Este método tradicional com armazenamento a $4^{\circ} \mathrm{C}$ prevê um intervalo entre repicagens de sete a oito semanas, pois a maioria das bactérias fitopatogênicas não sobrevive após este tempo (5). No entanto, no presente estudo, Aac repicada mensalmente sobreviveu durante todo o período testado (180 dias) começando a perder a viabilidade apenas aos 90 dias (Figura 1). Nos demais métodos, os isolados perderam a viabilidade no decorrer das avaliações, tendo a preservação em água declinado em eficiência até $0 \%$ aos 180 dias. No método de folhas herborizadas, observou-se grande oscilação na porcentagem de recuperação pelo reisolamento. Isto pode ser explicado porque folhas e lesões diferentes foram utilizadas a cada amostragem e os tecidos dessecados foram conservados à temperatura ambiente. $\mathrm{O}$ método de folhas herborizadas é aplicável para a maioria das bactérias fitopatogênicas (7), tendo preservado a viabilidade e patogenicidade de Pseudomonas syringae pv. glycinea em soja por nove anos (2). Por outro lado, a recuperação de Aac a partir de material herborizado sugere que a bactéria pode sobreviver em restos de culturas que pode servir como fonte de inóculo primário para novos plantios.

Com relação à manutenção da patogenicidade de Aac, a dessecação em papel de filtro e as repicagens periódicas propiciaram os maiores valores de áreas abaixo das curvas da incidência da doença e do índice de doença, sem diferirem $(\mathrm{P}=0,05)$ entre si (Tabela 1$)$. Apesar da maioria dos trabalhos sobre preservação de bactérias fitopatogênicas avaliarem apenas a viabilidade das culturas, o método de repicagens periódicas, segundo Romeiro (7), tem como desvantagens após sucessivas transferências, a perda da patogenicidade ou virulência, além do comprometimento da estabilidade genética.

Recomenda-se, portanto a dessecação em papel de filtro para preservação de Aac a longo prazo (no mínimo 180 dias), enquanto que a curto prazo indica-se o método de repicagens periódicas, com intervalos mensais.

Tabela 1. Eficiência de métodos de preservação de Acidovorax avenae subsp. citrulli, avaliada pelas áreas abaixo das curvas de incidência da doença (AAINC) e do índice de doença (AAIDO), durante 180 dias.

\begin{tabular}{lccc}
\hline Método de preservação & AAINC $^{1}$ & AAIDO $^{1}$ \\
\hline Dessecação em papel de filtro & $500,0 \mathrm{a}^{2}$ & 292,3 a \\
Repicagens periódicas & $393,8 \mathrm{ab}$ & $283,8 \mathrm{a}$ \\
Água & $340,0 \mathrm{bc}$ & $208,3 \mathrm{~b}$ \\
Folhas herborizadas & $283,3 \mathrm{c}$ & $110,0 \mathrm{c}$ \\
\hline
\end{tabular}

${ }^{1}$ Calculadas conforme Shaner \& Finney (7), utilizando os dados mensais de incidência da doença e de índice de doença.

${ }^{2}$ Média de oito repetições. Médias seguidas pela mesma letra na vertical não diferem significativamente entre si pelo teste de Tukey ( $\left.\mathrm{P}=0,05\right)$. 


\section{AGRADECIMENTOS}

Os autores são gratos à Fundação de Amparo à Ciência e Tecnologia do Estado de Pernambuco - FACEPE, pelo auxílio financeiro.

\section{REFERÊNCIAS BIBLIOGRÁFICAS}

1. Araújo, D.V.; Mariano, R.L.R.; Michereff, S.J. Métodos de inoculação de Acidovorax avenae subsp. citrulli em melão. Summa Phytopathologica, Botucatu, v.31, n.1, p.66-70, 2005.

2. Ferreira, L.P.; Romeiro, R.S. Ampliação de cultivares da série diferenciadora de raças fisiológicas de Pseudomonas syringae pv. glycinea em soja. Fitopatologia Brasileira. Brasília, v.11, p.335, 1986.

3. Jones, J.B.; Gitaitis, R.D.; Schaad, N.W. Acidovorax and Xylophilus. In: Schaad, N.W.; Jones, J.B.; Chun, W. (Eds.) Laboratory guide for identification of plant pathogenic bacteria. St Paul: APS Press, 2001. p.121-138.
4. Mariano, R.L.R.; Silveira, E.B. Mancha-aquosa: importante bacteriose do meloeiro no Brasil. Anais da Academia Pernambucana de Ciência Agronômica, Recife, v.1, p. 79-88, 2004.

5. Mariano, R.L.R.; Silveira, E.B. (Coord.). Manual de práticas em fitobacteriologia. Recife: UFRPE, 2005.

6. Mckinney, R.H. Influence of soil temperature and moisture on infection of wheat seedlings by Helminthosporium sativum. Journal of Agricultural Research, Washington, v.26, p.195-218, 1923.

7. Romeiro, R.S. Preservação de bactérias fitopatogênicas. In: Romeiro, R.S. Métodos em bacteriologia de plantas. Viçosa: UFV, 2001. p.87-96.

8. Shaner, G.; Finney, R.E. The effect of nitrogen fertilization on the expression of slow-mildewing resistance in knox wheat. Phytopathology, St. Paul, v.15, n.2, p.1051-1056, 1977.

9. Takatsu, A. Coleção de bactérias fitopatogênicas preservadas pelo método de dessecação em tirinhas de papel. Informações de dez anos. Fitopatologia Brasileira, Brasília, v.5, n.2, p.315, 1994 . 